\title{
Discourse Analysis of Naturally Occurring Data: The Relational Development of Mindfulness
}

\author{
Abstract \\ Discourse analysis allows qualitative researchers to investigate the ways people \\ relationally construct realities through language use, especially through speaking and \\ writing. To understand talk and text as relational practices, we pay close attention to \\ the active dimensions of discourse: its construction, function and variation in specific \\ social and historical contexts. The data used in this exemplar is provided by $\mathrm{Dr}$ \\ Steven Stanley from Cardiff University and Dr Rebecca Crane from the Centre for \\ Mindfulness Research and Practice at Bangor University and is taken from a project \\ investigating the social construction of mindfulness within Mindfulness-Based \\ Cognitive Therapy (MBCT). The project received ethical clearance from the research \\ ethics and governance committee of the School of Psychology at Bangor University \\ and the North Wales Research Ethics Committee. The project contributes findings to \\ developing traditions of mindfulness research, training of mindfulness teachers, and \\ qualitative research on education, training, health, medicine and psychotherapy. The \\ data comprises a transcription of institutional interaction between an MBCT teacher \\ and her students. In this session there are just three participants present - the other \\ three course members are absent due to illness. The course is held in an outpatient \\ oncology unit. The students meet weekly for 2-hour sessions. MBCT is an eight-week \\ psychoeducational course and our data is an extract taken from week two of a \\ course for people with cancer. Six people are enrolled on the course and three \\ female participants are present during this class. The exemplar will help you to \\ analyse naturally occurring interaction, think about power dynamics and teacher \\ dilemmas in pedagogy, and the possible functions of psychological terms in \\ interaction such as 'mind'.
}

\section{Discourse Analysis of Interaction}


Qualitative research in the social sciences and humanities - such as in sociology, social psychology, or history - is largely conducted through speaking and writing. Researchers observe people interacting, speak with participants in interviews and gather written documents. They write books and articles, combining a specialist technical vocabulary with 'ordinary' language words. We could argue that qualitative research is mostly 'discourse': forms of talk and texts, understood as social practices (Potter \& Wetherell, 1987). If we removed language use from history, socio-cultural life and social research, what would be left?

To analyse 'talk' and discourse, qualitative data is often created through researchers' staged interactions with participants, especially in interviews. In this case, the authors have collected and carefully transcribed some 'naturally-occurring' talk, to find out what happens in a particular domain of social life. Discourse analysis involves studying the function, construction and variation of talk and texts, which are understood as social practices. We analyse what people are doing with their words and how they do it. When we conduct a discourse analysis, we get interested and curious in the detail of people's active uses of language, and how they construct social and psychological realities through speech and writing.

Critical discursive social psychology is influenced by sociological traditions of ethnomethodology (the study of people's everyday sense-making practices), conversation analysis (the study of how talk-in-interaction works), and rhetoric (the study of argument and persuasion). We treat people's use of discourse, here within 'institutional' interaction, as active and situated socially, culturally and historically. Institutional interaction is a special kind of talk which often occurs in workplace settings where speakers possess different speaking rights and entitlements, for example in terms of who gets to initiate the interaction (doctor/patient; teacher/student).

\section{Data Exemplar: The Social Construction of Mindfulness in Mindfulness- Based Cognitive Therapy}


This particular dataset exemplar comes from a project that investigates the social construction of mindfulness in mindfulness-based courses in the United Kingdom (UK). Courses in mindfulness meditation are being integrated into European mental health care, education and workplaces such as the UK government. Notably Mindfulness-Based Cognitive Therapy (MBCT) is available on the National Health Service (NHS) as a treatment for depression. Yet researchers have expressed concerns about mindfulness-based applications outpacing their scientific evidence base; disagreements about the nature of 'mindfulness'; and how mindfulness should be studied (see Williams \& Kabat-Zinn, 2013). Arguably we need a greater range of methodological approaches to mindfulness research.

This project extends mainstream clinical psychological research on mindfulness by analysing interactions between mindfulness teachers and people learning mindfulness. 'Mindfulness' is sometimes taken for granted by researchers as an inner private psychological state or trait. Psychologists tend to measure mindfulness using questionnaires or hypothesise its existence as a cognitive mechanism in experiments. This project extends and develops mindfulness research by conceptualising mindfulness as involving relational, discursive practices. What does mindfulness look like in practice? How do mindfulness teachers and students develop 'mindfulness' in their interactions? What dilemmas do mindfulness teachers negotiate as they teach?

The dataset exemplar is a transcription of the audio of an interaction occurring between a female experienced mindfulness teacher and three females diagnosed with cancer, during the second week of an eight week Mindfulness-Based Cognitive Therapy (MBCT) psycho-educational course. Following a 45-minute guided 'body scan' meditation practice, in which the mindfulness students are lying on their backs and the teacher is sitting on a meditation stool, the teacher rearranges the students to be seated in chairs in front of the teacher. The five minutes of interaction took place immediately following the body scan. The audio of the interaction has been transcribed using a simplified Jefferson-style transcription, as used for conversation 
analysis, which captures how teachers and students speak (for a more detailed explanation, see Wooffitt, 2005).

\section{Single Case Analysis: Discourse, Rhetoric and Social Construction}

Discourse and conversation analysts commonly collect together interactional and/or textual data and look for common patterns of social organisation across a data corpus. By contrast, this single case allows us to analyse in detail how mindfulness is taught across a sequence of turns in interaction. There are different varieties of interaction analysis and no commonly agreed method. One way is to analyse the 'little words' in interaction along with broader patterns of sense-making. To do this, we need to capture what is said by all parties, along with conducting scholarship to contextualise the interaction. In what follows, Drs Steven Stanley and Rebecca Crane detail how they went about analysing this particular transcript of naturally occurring data.

\section{Tracing the History of Mindfulness}

When we speak, write or think, we do not do so anew, but use a shared language and common sense. When we use discourse, we enter into the long conversation of history. Thus our analysis could begin with historical scholarship of the 'mindfulness movement'. It has been claimed, for example, that mindfulness is a historically recent secular 'movement' in North American and European societies, with mindfulness meditation becoming integrated into mainstream western institutions, such as health, education, and business. We might then begin by tracing the history of the word 'mindfulness' and related common sense language of 'mind' and 'body'. This would involve conducting a 'history of the present', specifically a history of the 'present moment' in so-called 'third wave' acceptance-based psychotherapies, which draw upon ancient and modern Buddhist ideas and practices. For example, KabatZinn (1994) defined mindfulness as an awareness which arises when we pay 
attention in a particular way: on purpose, in the present moment, and without judgement moment by moment. While mindfulness is a little word, it is arguably now also a big noun, being promoted by university research centres and multinational corporations.

\section{The Cultural Status of Mindfulness}

Historical scholarship could be complemented by cultural analysis of the influence of ancient and modern Buddhist traditions upon the integration of mindfulness courses into Western institutions. Speaking and writing about mindfulness arguably involves taking up a modern secular therapeutic stance focused upon 'wellbeing' and practical benefits to be accrued through the practice of mindfulness meditation. We might therefore also situate how 'mindfulness' is understood in secular mindfulness courses in a way which is both influenced by, but also distinct from, its use in Buddhist contexts. A cultural analysis of mindfulness in society might help us to situate the secular vocabulary of 'mindfulness' within the discourses of the psychological sciences, psychosomatic therapies and alternative spiritualities. As an example, we could look at how people learn to govern themselves and take responsibility for their mental states as they learn mindfulness.

\section{The Rhetoric of Mindfulness}

Analysing the historical and cultural contexts of mindfulness is important, but it is equally important to study how mindfulness is taught. There are only a few studies of mindfulness in action and how it is taught and learnt within standardised and manualised mindfulness courses such as MBCT. So to inform our analysis of the local rhetorical context of the mindfulness class, we might usefully draw upon ethnographies of Buddhist retreat centres, and conversation analyses of pedagogic and therapeutic interactions. We could frame the analysis of institutional interaction within this specific MBCT course as a possible hybrid of 'secular religion', 'psychoeducation' and 'psychotherapy'. 
What makes this interaction institutional? We could analyse systematic patterning of questions and answers, such as the familiar 'three-turn sequence' common in pedagogic teaching and learning discourse. In this sequence, the teacher asks a question (first turn), which is followed by the students' answer (second turn) and then the turn routinely goes back to the teacher who gives a response (third turn) (Lee, 2007). We found this characteristic three-turn sequence to be consistently employed by the teacher during the inquiry sequences of mindfulness courses. Notice how in the data the mindfulness teacher initiates the interaction and asks a question (lines 1-8) (first turn). Following a second-turn response from a student (line 10), the teacher offers a third turn where she responds to and acts upon the student's turn (lines 11-12), thereby moving the interaction forward. Notice also how the teacher revises what the student has said. We return to analyse this sequence further below.

Important to this exemplar, we can study how students in an MBCT class learn a language of mindfulness, including a specialised vocabulary for describing experiences. We might look at how words such as 'practice' (e.g. 1-5, 176-177), 'notice' (e.g. 4, 8, 12), 'automatic' (104) and 'commentary' (118) are used by the teacher and perhaps eventually by the students themselves, as beginner 'mindfulness practitioners'. In the 'inquiry' sequence above, the students are not merely describing what happened during a prior mindfulness meditation practice, but arguably are learning a new way of orienting to their experience. To what extent do the teacher and her students collaboratively accomplish this reorientation? Mindfulness teaching might be seen to be a rhetorical practice, as teachers employ skills of argument to persuade students of the benefits of a mindful orientation during the teaching of mindfulness itself.

The word 'mindfulness' is perhaps misleading, because most practitioners would understand mindfulness meditation as an embodied practice. Indeed, they would be unlikely to argue 'mind' and 'body' are distinct substances, like the philosopher Descartes did. Nevertheless teachers and students refer to (the, my, or your) 'mind' (or attention) going (47), moving (52), wandering (57), hopping away (141), jumping 
off (143). Analytic philosophers like Ryle and Coulter might argue these claims are misleading: the mind is not an entity or a place. Whilst mindfulness teachers may, contrary to Descartes, argue introspective awareness requires training and is not incorrigible, they may still imply 'the mind' is an inner, private entity. Following the philosopher Wittgenstein, we might challenge this by exploring the varying functions of psychological terms like 'mind' in the ongoing interaction. What are their uses? Perhaps the teacher is using 'mind' as a placeholder for the word 'attention'. Perhaps 'mind' is being used in its lay sense.

Mindfulness pedagogy appears to involve a 'disciplined improvisation' (Crane et al., 2014). The mindfulness teacher skilfully balances a dilemma between adhering to a pre-established standardised form and responding to the changing moments of interaction with participants. On the one hand, the teacher encourages students to share what they experienced and 'what you noticed', thereby encouraging student participation. On the other hand the teacher also exerts control and an authoritative constraint on the content and extent of student contributions (e.g. 'little snippets little, little words' about 'this practice'). How and when does the teacher vary between allowing and limiting contributions (e.g. 65-69)? Relatedly, how and when does the teacher veer between opening the floor for students to self-select contributions (e.g. 4-8, 51-52) and then selecting specific students to contribute (e.g. 57, 72-73)? We might map the 'institutional' elements and power dynamics of this interaction, how dialogue is opened up and closed down, which would illustrate both the structure and agency of this setting.

This mindfulness teacher seems to be negotiating a dilemma. On the one hand, teachers have a specific curriculum to teach, with predetermined content; on the other hand, they want students to learn for themselves through their experience. Part of this learning concerns how to respond to the immediacy of experience; from a practitioner point of view, it is critical that this is modelled through the process of teaching and learning itself. In mindfulness teacher training, this is referred to as adhering to the 'form' of the syllabus whilst connecting with the 'essence' of mindfulness. 
Perhaps one of the ways in which mindfulness teachers practically manage and attempt to resolve this dilemma is by echoing and reconstructing student responses to questions. For example, the teacher asks students to provide 'little snippets', 'little words' or 'different parts' of their experience (4-8). When a student offers an extended turn (10) the teacher interrupts them mid-turn and offers a so-prefaced reformulation which simultaneously echoes and repairs the students' contribution (11-12). The noticing that it is 'easier' to focus in class than at home is repaired to 'ease of focus' which fulfils the criteria of being a 'little' snippet or word concerning the prior body scan, rather than a more lengthy comparison between experience of practicing in class versus at home. Through her third-turn response the teacher heads off an extended comparative utterance. When several students make similar comments simultaneously about 'it' being 'easier' in class, the teacher repairs again with 'okay (.) it's easier to focus right' (18), conceding the comparative emphasis of 'easier'. The subsequent answers perhaps fulfil the criteria of being succinct but retain an evaluative comparative emphasis: 'getting easier' (19), 'very difficult (.) still' (27).

\section{Private Thoughts in Interaction}

We might relatedly explore how mindfulness teachers align the standardised syllabus of MBCT with the nonstandard experience of students learning mindfulness meditation. A predefined learning outcome for week two of an MBCT course and of the 'body scan' meditation practice is an awareness of 'mind wandering'. Mind wandering is when the attention automatically moves away from being focused upon bodily sensations during the body scan meditation. The meditator may be thinking but not aware that they are thinking. Mindfulness practice involves gradually learning to notice where the mind goes and to gently bring it back to where we intended it to be. This awareness of mind wandering is described in the psychological literature as 'decentring' or 'meta-cognitive awareness'. How is decentring taught in practice? 
The teacher's frequently returning question of what students 'noticed' is perhaps an illustration of the teaching of decentring. Later the teacher questions whether a student 'knew' or was 'aware' that their mind wandered. Possible demonstrations of decentring occur during the several instances of 'reported private thoughts' (e.g. 83$84,162-163,167-168)$. This is when a speaker claims to report the inner private thoughts of themselves or another, often pre-empted by a quotative 'I thought' ('the voice comes back', 171). For example, 'oh for goodness sake what are you doing' (161). Barnes and Moss (2007) most commonly found reported private thoughts in interview data, especially in interviews about mindfulness. They say that mindfulness practice encourages 'the kind of self-accounts where inner dialogue can be easily and relevantly topicalized' (p. 142). But they caution against seeing reported private thoughts as mirroring or representing what people were actually thinking. Instead they suggest 'active voicing' functions to perform various social, moral and practical tasks and negotiate dilemmas in interaction. The job of the analyst is to study these functions.

Perhaps then a key function of reporting private thoughts in a mindfulness class is to demonstrate an ability to 'see thoughts as thoughts' and as mental entities. According to Wilson (2014), mindfulness students are being implicitly taught to become 'good', mindful individuals, aware and knowing of their wandering minds, rather than unmindful individuals, who are unaware of their mental activities (see 112-115 for a possible example of this). However, claims about a moral dualism between mindful/unmindful would need to be evidenced through analysis; perhaps mindfulness courses contain non-dual or holistic teachings regarding the morality of being mindful.

\section{Reflective Questions}

1. Why might you want to conduct a discourse analysis of interaction in this way - that is, looking at the details of what people say?

2. Find a 'three-turn sequence' in the interaction. Does the teacher revise what the student says? 
3. How does the mindfulness teacher balance egalitarianism (by encouraging student participation) and authoritarianism (by establishing teacher control)?

4. Find a 'reported private thought'. What is the speaker doing with this phrase?

5. How is 'mind' constructed in the interaction?

\section{Further Reading}

Barnes, R., \& Moss, D. (2007). Communicating a feeling: the social organization of 'private thoughts'. Discourse Studies, 9(2), 123-148.

Billig, M., Condor, S., Edwards, D., Gane, M., Middleton, D., \& Radley, A. (1988). Ideological dilemmas: A social psychology of everyday thinking. London, UK: SAGE.

Crane, R. S. (2009). Mindfulness-based cognitive therapy: Distinctive features. London, UK: Routledge.

Crane, R. S., Stanley, S., Rooney, M., Bartley, T., Cooper, L., \& Mardula, J. (2014). Disciplined improvisation: characteristics of inquiry in mindfulness-based teaching. Mindfulness. DOI: 10.1007/s12671-014-0361-8.

Dryden, W., \& Still, A. (2006). Historical aspects of mindfulness and self-acceptance in psychotherapy. Journal of Rational-Emotive and Cognitive-Behavior Therapy, 24(1), 3-28.

Edwards, D., \& Mercer, N. (1987). Common knowledge: The development of understanding in the classroom. London, UK: Routledge.

Emanuelsson, J., \& Sahlstrom, F. (2008). The price of participation: teacher control versus student participation in classroom interaction. Scandinavian Journal of Educational Research, 52(2), 205-223.

Kabat-Zinn, J. (1994). Wherever you go, there you are: Mindfulness meditation for everyday life. London, UK: Piatkus.

Lee, Y. O. (2007). Third turn position in teacher talk: contingency and the work of teaching. Journal of Pragmatics, 39, 180-206.

Potter, J. and Wetherell, M. (1987). Discourse and social psychology: Beyond attitudes and behaviour. London, UK: SAGE. 
Stanley, S. (2014). Mindfulness. In T. Teo (Ed.), Encyclopedia of critical psychology (pp. 1186-1191). London, UK: Springer.

Williams, J. M. G., \& Kabat-Zinn, J. (2013). Mindfulness: Diverse perspectives on its meaning, origins and applications. London, UK: Routledge.

Wilson, J. (2014). Mindful America: The mutual transformation of Buddhist meditation and American culture. Oxford, UK: Oxford University Press.

Wooffitt, R. (2005). Discourse analysis and conversation analysis: A comparative and critical introduction. London, UK: SAGE. 